\begin{tabular}{|c|c|}
\hline Citation & $\begin{array}{l}\text { Kang Cui, Oleksandr Ivasenko, Kunal S. Mali, Dongqing Wu, Xinliang Feng, } \\
\text { Klaus Müllen, Steven De Feyter, and Stijn F. L. Mertens } \\
\text { Potential-driven molecular tiling of a charged polycyclic aromatic } \\
\text { compound } \\
\text { Chemical Communications, } 2014,50,10376 \text { - } 10378\end{array}$ \\
\hline Archived version & $\begin{array}{l}\text { Author manuscript: the content is identical to the content of the published } \\
\text { paper, but without the final typesetting by the publisher }\end{array}$ \\
\hline Published version & $\begin{array}{l}\text { insert link to the published version of your paper } \\
\text { http://dx.doi.org/10.1039/c4cc04189e }\end{array}$ \\
\hline Journal homepage & $\begin{array}{l}\text { insert link to the journal homepage of your paper } \\
\text { http://pubs.rsc.org/en/journals/journal/cc }\end{array}$ \\
\hline Author contact & $\begin{array}{l}\text { your email steven.defeyter@kuleuven.be } \\
\text { your phone number + } 32(0) 16327921\end{array}$ \\
\hline IR & url in Lirias https://lirias.kuleuven.be/handle/123456789/477326 \\
\hline
\end{tabular}

(article begins on next page) 


\title{
COMMUNICATION
}

Cite this: DOI: 10.1039/xoxxooooox

Received ooth January 2012,

Accepted ooth January 2012

DOI: $10.1039 / \times 0 x x 00000 x$

www.rsc.org/

\section{Potential-driven molecular tiling of a charged polycyclic aromatic compoundt}

\author{
Kang Cui, ${ }^{a}$ Oleksandr Ivasenko, ${ }^{a}$ Kunal S. Mali, ${ }^{a}$ Dongqing Wu, ${ }^{b}$ Xinliang Feng, ${ }^{b}$ \\ Klaus Müllen, ${ }^{b}$ Steven De Feyter, ${ }^{* a}$ and Stijn F. L. Mertens* ${ }^{a c}$
}

Using in situ electrochemical scanning tunnelling microscopy (EC-STM), we demonstrate fully reversible tuning of molecular tiling between self-assembled structures with supramolecular motifs containing 2, 3, 4, 6 or 7 tectons. The structures can be explained by electrocompression of the cationic adlayer at the solid-liquid interface.

In supramolecular chemistry, as in biology, the functionality of a structure is often determined by the accuracy with which this structure can be built. Therefore, in the field of self-assembly, the interplay between molecular design and external stimuli to achieve a high level of structural control remains a very active research topic. ${ }^{1}$ Ultimate control over tectonic arrangement in supramolecular compounds and structures is expected to yield unprecedented efficiency of catalysts and selectivity of artificial sensors, as it would allow tuning structure-reactivity relationships at will.

In this work, we present a system based on an organic salt (polyaromatic $\mathrm{PQPC}_{6}{ }^{+}$cation + anthraquinonedisulfonate $\mathrm{AQDSA}^{2-}$ dianion, Figure 1) that, depending on the substrate potential, can be reversibly assembled into patterns whose structural motifs contain from 2 up to 7 building blocks or tectons. As the motifs are separated by subnanometre-sized gaps, they could form the basis for surface-grown atomically precise polymers, ${ }^{2}$ electrocatalytic surfaces with high selectivity ${ }^{3}$ or artificial receptors. ${ }^{4}$ To our knowledge, this is the first example of electrochemically controlled molecular tiling using organic molecules that carry a permanent charge, although attempts in this direction using ionic liquids are actively pursued. ${ }^{5}$

The studied compound was synthesised as previously described, ${ }^{6}$ and drop-cast on a flame-annealed $\mathrm{Au}(111)$ single crystal (miscut < $0.1^{\circ}$, Mateck $\mathrm{GmbH}$, Jülich) by evaporating a drop of saturated solution in ethanol. After rinsing with absolute ethanol and evaporation of the solvent in an Ar (5.0, Air Liquide) stream, selfassembled structures were visualised by EC-STM in $0.1 \mathrm{M} \mathrm{HClO}_{4}$, using a lab-built ${ }^{7}$ or Agilent 5100 STM + Picostat bipotentiostat and electrochemically etched $\mathrm{W}$ tips that were polymer-coated to suppress faradaic current. All measurements were carried out in an Ar atmosphere, and potentials are reported versus the reversible hydrogen electrode (RHE).
Figure 1 shows the cyclic voltammogram $(\mathrm{CV})$ of the bare and (PQPC 6$)_{2} \mathrm{AQDSA}$-modified $\mathrm{Au}(111)$ in $0.1 \mathrm{M} \mathrm{HClO}_{4}$. In the available potential window between hydrogen evolution and gold oxidation, two pairs of peaks are apparent, and are of different origin. At intermediate potentials, a well-separated pair of peaks $\mathrm{P} 1 / \mathrm{P} 1$ ' is present, which we ascribe to a phase transition in the $\mathrm{PQPC}_{6}{ }^{+}$adlayer (vide infra), as the $\mathrm{PQPC}_{6}{ }^{+}$cation itself is not redoxactive under the experimental conditions. ${ }^{8}$ The charge under the peaks $\mathrm{P} 1$ and $\mathrm{P} 1$ ' is identical within the accuracy of integration, and remained constant on continued cycling. The positive-going peak, however, is considerably sharper than in the opposite direction $\left[\mathrm{fwhm}(\mathrm{P} 1)=22 \mathrm{mV}\right.$; fwhm $\left.\left(\mathrm{P} 1^{\prime}\right)=38 \mathrm{mV}\right]$, which may indicate a difference in phase transition dynamics. The peak separation of $c a$. $100 \mathrm{mV}$ between P1 and P1' expresses the energetic barrier for switching between the two structures. At more negative potentials, the anthraquinone-based dianion shows up through its reversible voltammetric behaviour (P2/P2'), as was confirmed by addition of 9,10-anthraquinone-2,6-disulfonic acid to the electrolyte (see ESI).

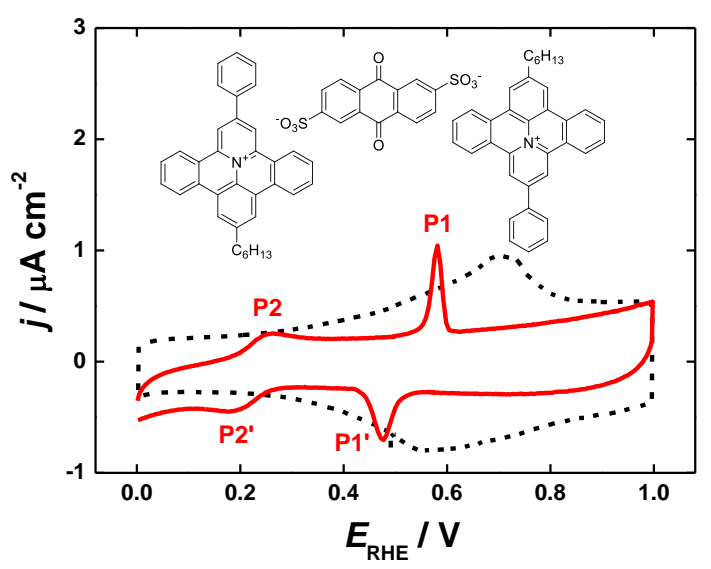

Fig. 1. Cyclic voltammogram of bare (black dotted trace) and $\left(\mathrm{PQPC}_{6}\right)_{2} \mathrm{AQDSA}-\mathrm{modified}$ (red trace) $\mathrm{Au}(111)$ in $0.1 \mathrm{M} \mathrm{HClO}_{4}$. Scan rate $10 \mathrm{mV} \mathrm{s}^{-1}$. Inset: structural formula of 9-hexyl-2phenylbenzo[8,9]quinolizino-[4,5,6,7-fed]phenanthridinylium 9,10anthraquinone-2,6-disulfonate ( $\left.\mathrm{PQPC}_{6}\right)_{2} \mathrm{AQDSA}$. 
Starting at substrate potentials positive from P1, Figure 2 shows the highly regular supramolecular structures observed for $0.6<E_{\mathrm{S}}<$ $0.8 \mathrm{~V}$; at even higher potentials, the adlayer amorphises (see ESI). The few missing molecules in the large-scale image together with the submolecular resolution achieved in Figure 2B for the majority phase allow to identify each bright spot as the fused aromatic system of the $\mathrm{PQPC}_{6}{ }^{+}$cation, and to propose the model superimposed on the STM image for the molecular packing. The structure can be fully described by considering a $\mathrm{PQPC}_{6}{ }^{+}$dimeric motif occupying identical positions in two alternating rows, which are shifted over $b / 2=1.7 \mathrm{~nm}$. Under the tunnelling conditions used, the $n$-hexyl chains were not visible, but according to our model occupy most of the pore-like feature next to every pair of molecules, producing a packing density of 0.47 molecules $\mathrm{nm}^{-2}$. A second polymorph, with almost identical packing density, is visible in the lower region of Figure 2A, and magnified in Figure 2C. This minority phase represented less than $20 \%$ of the ordered adlayer and was considerably less stable during scanning, which suggests that the majority phase (Figure 2B) is the thermodynamically most stable one. Strikingly, the dianion was never observed directly in the images, even though overall electroneutrality implies a position close to the visualised cation adlayer. In view of the abundance of $\mathrm{ClO}_{4}^{-}$in the electrolyte, exchange of the adlayer anions is likely. Preliminary experiments with $\mathrm{PQPC}_{6} \mathrm{ClO}_{4}$, in which the AQDSA ${ }^{2-}$ dianion was completely replaced with $\mathrm{ClO}_{4}{ }^{-}$, revealed the absence of any long-range order (see ESI). A detailed study of the structureinducing effect of the anion will be reported elsewhere. ${ }^{9}$
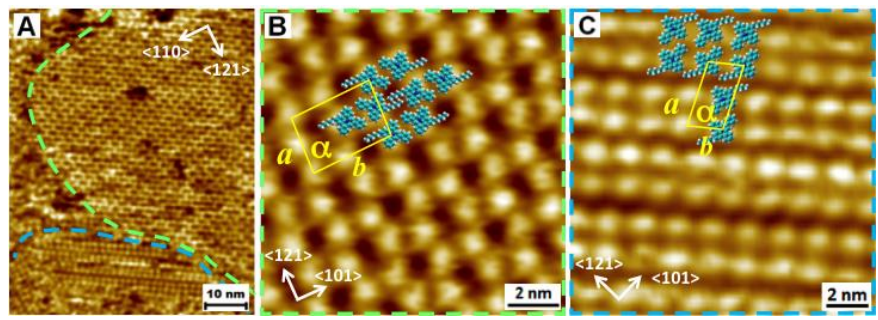

Fig. 2. (A) Large-scale EC-STM image of $\left(\mathrm{PQPC}_{6}\right)_{2} \mathrm{AQDSA}-$ modified $\mathrm{Au}(111)$ in $0.1 \mathrm{M} \mathrm{HClO}_{4}$ at substrate potential $E_{\mathrm{s}}=0.6 \mathrm{~V}$, showing two phases with a dimeric motif. High-resolution image of (B) majority phase with unit cell parameters $a=(2.5 \pm 0.1) \mathrm{nm}, b=$ $(3.4 \pm 0.2) \mathrm{nm}, \alpha=(88 \pm 2)^{\circ}$, and (C) minority phase with $a=(2.9 \pm$ $0.1) \mathrm{nm}, b=(1.6 \pm 0.1) \mathrm{nm}, \alpha=(69 \pm 2)^{\circ}$. Bias voltage $U_{\text {bias }}=-0.65$ $\mathrm{V}$; tunnelling current $I_{\mathrm{t}}=1 \mathrm{nA}$.

On crossing peak $\mathrm{P} 1$ ' in the $\mathrm{CV}$ to less positive potentials, an abrupt and complete phase transition is observed, now characterised by a hexameric motif of $\mathrm{PQPC}_{6}{ }^{+}$cations, Figure 3 . Again, the hexameric units within which close packing of the aromatic PQP cores occurs, are spaced by the $n$-hexyl chains that extend from the fused ring system. As clock- and counterclockwise arrangements of the cations constituting each hexameric motif are possible, mirrorimage domains were observed as expected (see ESI).

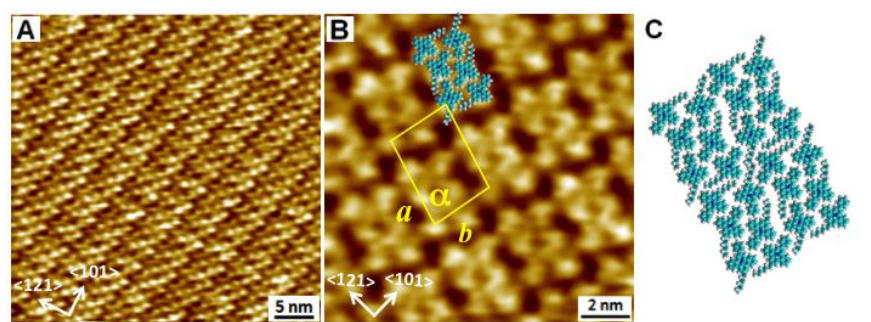

Fig. 3. (A) Large-scale and (B) high-resolution EC-STM images of $\left(\mathrm{PQPC}_{6}\right)_{2} \mathrm{AQDSA}-$ modified $\mathrm{Au}(111)$ in $0.1 \mathrm{M} \mathrm{HClO}_{4}$ at $E_{\mathrm{s}}=0.35 \mathrm{~V}$, showing hexameric motif. Unit cell parameters $a=(4.0 \pm 0.2) \mathrm{nm}, b$ $=(2.8 \pm 0.1) \mathrm{nm}, \alpha=(83 \pm 2)^{\circ}$. $U_{\text {bias }}=-0.65 \mathrm{~V} ; I_{\mathrm{t}}=1 \mathrm{nA}$. (C) Tentative model.

At potentials close to the peaks $\mathrm{P} 1 / \mathrm{P} 1$ ' in the voltammogram, occasionally lamellae consisting of tri- and tetrameric motifs were observed, Figure 4A, whereas at the most negative substrate potentials available $\left(E_{\mathrm{s}}<0.15 \mathrm{~V}\right)$, heptameric structures were also found, Figure 4B. This stepwise increase in lamellar width as a function of potential leads to a proportional increase in coverage, as the size of the close-packed supramolecular unit increases: the packing density in the hexameric structure $\left(0.54\right.$ molecules $\left.\mathrm{nm}^{-2}\right)$ has increased by $15 \%$ over the dimeric structure $\left(0.47\right.$ molecules $\left.\mathrm{nm}^{-2}\right)$. We propose that asymptotically, a completely compact adlayer structure may emerge with infinite lamellar width, and all $n$-hexyl chains desorbed, even though the available potential window did not permit its experimental confirmation as yet. A model of this hypothetical structure is shown in Figure 4C, and closely resembles the one observed when the $n$-hexyl chain is absent. ${ }^{10}$

To explain the mechanism behind the potential-induced molecular tiling, we consider that the tectons' permanent charge makes them strongly susceptible to electrostatic effects, which has even enabled fully reversible switching between porous and 3dimensional (bilayer) structures with a single-component system. ${ }^{8}$ The various structures that we observe are characterised by an increase in packing density, from 0.47 (dimeric motif) up to 0.54 (hexameric motif) molecules $\mathrm{nm}^{-2}$ and could increase up to 0.6 molecules $\mathrm{nm}^{-2}$ in the hypothetical fully compact structure of Figure $4 \mathrm{C}$. From the potential of zero charge $(\mathrm{pzc}=0.62 \mathrm{~V})^{11}$ of the reconstructed $\mathrm{Au}(111)-(22 \times \sqrt{3})$ surface in dilute perchloric acid solutions and the capacitive current in cyclic voltammetry (Fig. 1), we can formally estimate the charge density $q$ on the gold surface for the potentials where the different adlayers are observed, which varies from $0.6 \mu \mathrm{C} \mathrm{cm}^{-2}$ at $0.6 \mathrm{~V}$ to $11.4 \mu \mathrm{C} \mathrm{cm}^{-2}$ at $0.1 \mathrm{~V}$.

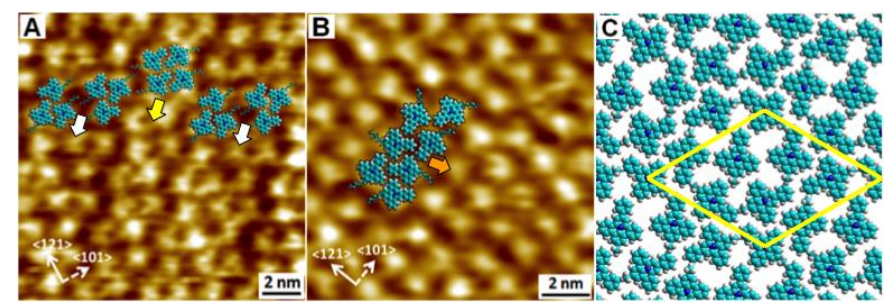

Fig. 4. (A) Tri- and tetrameric motifs at $E_{\mathrm{s}}=0.5 \mathrm{~V}$, and (B) heptameric motif at $E_{\mathrm{s}}=0.1 \mathrm{~V}$. $U_{\text {bias }}=-0.65 \mathrm{~V} ; I_{\mathrm{t}}=1 \mathrm{nA}$. (C) Hypothetical most compact structure at strongly negative substrate potentials.

The unit cell parameters of the various adlayers, on the other hand, yield charge densities between $7.5 \mu \mathrm{C} \mathrm{cm}^{-2}$ for the dimeric structure and $9.6 \mu \mathrm{C} \mathrm{cm} ~^{-2}$ for the hypothetical, most compact structure. As for most potentials $q\left(\mathrm{PQPC}_{6}{ }^{+}\right)>|q(\mathrm{Au})|$, these numbers indicate that the adsorption is $\pi$-electron driven (the adsorption energy of the fused aromatic rings is on the order of $\left.200 \mathrm{~kJ} \mathrm{~mol}^{-1}\right)^{12}$, and also explain why for positive surface charges the adlayer amorphises, as the molecules retain sufficient lateral mobility to be considered a 2-dimensional molecular gas. As the negative charge density on the substrate increases, the sterically expensive compression of the adlayer is favoured electrostatically, Figure 5. 


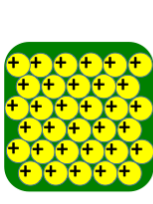

compact
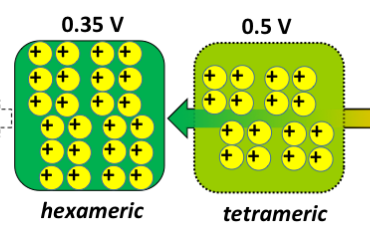
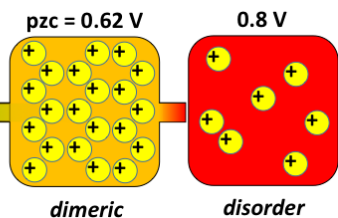

Fig. 5. Conceptual summary of adlayer electrocompression, indicating substrate potentials and motifs observed in STM.

Adlayer electrocompression has been described previously by Broekmann et al. for inorganic iodide on copper, ${ }^{13}$ but was to our knowledge never demonstrated for organic ions. Obviously, the comparatively rich structural features of the $\mathrm{PQPC}_{6}{ }^{+}$cations allow for a larger variety of supramolecular effects in the present case. Compared to uncharged molecules, whose supramolecular behaviour at the solid-liquid interface has been studied abundantly, we underline that organic ions increase the degree of control that can be exerted over the self-assembly at electrochemical interfaces, and invite the synthetic community to explore this parameter even more vigorously than to date, which may open the way to fully deterministic (as opposed to random ${ }^{14}$ ) molecular tiling.

In conclusion, we have demonstrated molecular tiling of organic ions at a metal-electrolyte interface, with fast and reversible potential control over the supramolecular arrangement. Key elements in the design of new tectons are the polyaromatic character on the one hand, providing strong adsorption on gold, and permanent, non-redoxactive charge, increasing their susceptibility to electrochemical potential as a structuring principle. Forthcoming work could apply this principle as a first step towards the on-surface formation of polymers with atomic accuracy (by integrating photopolymerisable moieties) or highly selective in situ constructed sensor surfaces.

This work was supported by the China Scholarship Council through a PhD scholarship to K.C., and by the European Commission through a Marie Curie European reintegration grant to S.F.L.M., and further by grants from the Fund for Scientific Research - Flanders (FWO - Vlaanderen) and Advanced ERC grant OxideSurfaces. The research leading to these results has also received funding from KU Leuven (GOA 11/003), Belgian Federal Science Policy Office (IAP-7/05), and the European Research Council under the European Union's Seventh Framework Programme (FP7/2007-2013)/ERC Grant Agreement no. 340324.

\section{Notes and references}

a Department of Chemistry, KU Leuven, Celestijnenlaan 200F, 3001 Leuven (Belgium).

${ }^{b}$ Max Planck Institute for Polymer Research, Ackermannweg 10, 55128 Mainz (Germany).

${ }^{c}$ Institut für Angewandte Physik, TU Wien, Wiedner Hauptstraße 810/E134, 1040 Wien (Austria).

E-mail: steven.defeyter@chem.kuleuven.be (S. De Feyter); stmerten@ gmail.com (S. F. L. Mertens)

$\dagger$ Electronic Supplementary Information (ESI) available: See DOI: $10.1039 / \mathrm{c} 000000 \mathrm{x} /$

1 (a) T. Fukino, H. Joo, Y. Hisada, M. Obana, H. Yamagishi, T. Hikima, M. Takata, N. Fujita, T. Aida, Science 2014, 344, 499; (b) P. Deshmukh, M. Gopinadhan, Y. Choo, S. K. Ahn, P. W. Majewski, S
Y. Yoon, O. Bakajin, M. Elimelech, C. O. Osuji and R. M. Kasi, ACS Macro Lett., 2014, 3, 462; (c) X. Yan, T. R. Cook, J. B. Pollock, P. Wei, Y. Zhang, Y. Yu, F. Huang and P. J. Stang, J. Am. Chem. Soc., 2014, 136, 4460; (d) Y. Guillemin, J. Ghanbaja, E. Aubert, M. Etienne and A. Walcarius, Chem. Mater., 2014, 26, 1848; (e) R. Sun, C. Xue, X. Ma, M. Gao, H. Tian and Q. Li, J. Am. Chem. Soc., 2013, 135, 5990.

2 M. Bieri, M. Treier, J. Cai, K. Aït-Mansour, P. Ruffieux, O. Gröning, P. Gröning, M. Kastler, R. Rieger, X. Feng, K. Müllen and R. Fasel, Chem. Commun. 2009, 6919.

3 A. Kuzume, E. Herrero, J. M. Feliu, E. Ahlberg, R. J. Nichols and D. J. Schiffrin, Phys. Chem. Chem. Phys. 2005, 7, 1293.

4 Artificial Receptors for Chemical Sensors (Eds: V. M. Mirsky, A. K. Yatsimirsky), Wiley-VCH, Weinheim, 2011.

5 (a) M. Gnahm, C. Berger, M. Arkhipova, H. Kunkel, T. Pajkossy, G. Maas and D. M. Kolb, Phys. Chem. Chem. Phys., 2012, 14, 10647; (b) F. Endres, N. Borisenko, S. Zein El Abedin, R. Hayes and R. Atkin, Faraday Discuss., 2012, 154, 221.

6 (a) X. Feng, V. Marcon, W. Pisula, M. R. Hansen, J. Kirkpatrick, F. Grozema, D. Andrienko, K. Kremer, K. Müllen, Nature Mater. 2009, 8, 421; (b) D. Wu, L. Zhi, G. J. Bodwell, G. Cui, N. Tsao, K. Müllen, Angew. Chem. Int. Ed. 2007, 46, 5417; (c) D. Wu, W. Pisula, V. Enkelmann, X. Feng, K. Müllen, J. Am. Chem. Soc. 2009, 131, 9620.

7 M. Wilms, M. Kruft, G. Bermes and K. Wandelt, Rev. Sci. Instrum. 1999, 70, 3641.

8 K. Cui, K. S. Mali, O. Ivasenko, D. Wu, X. Feng, M. Walter, K. Müllen, S. De Feyter and S. F. L. Mertens, submitted.

9 K. Cui et al., in preparation.

10 K. S. Mali, D. Wu, X. Feng, K. Müllen, M. Van der Auweraer and S. De Feyter, J. Am. Chem. Soc. 2011, 133, 5686.

11 (a) D. M. Kolb, J. Schneider, Electrochim. Acta 1986, 31, 929; (b) U. W. Hamm, D. Kramer, R. S. Zhai, D. M. Kolb, J. Electroanal. Chem. 1996, 414, 85.

12 (a) P. V. C. Medeiros, G. K. Gueorguiev, S. Stafström, Phys. Rev. B 2012, 85, 205423; (b) W. D. Wheeler, B. A. Parkinson, Y. Dahnovsky, J. Chem. Phys. 2011, 135, 024702; (c) C. B. France, P. G. Schroeder, J. C. Forsythe, B. A. Parkinson, Langmuir 2003, 19, 1274 .

13 (a) P. Broekmann, A. Spaenig, A. Hommes and K. Wandelt, Surf. Sci. 2002, 517, 123; (b) B. Obliers, P. Broekmann and K. Wandelt, J. Electroanal. Chem. 2003, 554, 183.

14 M. O. Blunt, J. C. Russell, M. del Carmen Giménez-López, J. P. Garrahan, X. Lin, M. Schröder, N. R. Champness and P. H. Beton, Science 2008, 322, 1077. 